\title{
Conhecimentos ou competências: o que transmitir? ${ }^{2}$
}

Marie Duru-Bellat

Professora de Sociologia na Universidade de Borgonha
Resumo: A partir do pressuposto de que é central definir o que se julga bom e necessário de transmitir aos alunos, a autora reflete sobre a questão curricular a partir do debate de uma antiga polêmica: deve-se priorizar a transmissão de competências ou saberes aos alunos? É retomada a discussão da noção de competências e sua entrada na escola, o advento dos sistemas de avaliação calcados em competências e as dificuldades em sua operacionalização, as questões que o trabalho com a noção em debate podem suscitar aos educadores, e a existência do que chama de uma "ditadura do útil”3.

Palavras-chave: Currículo. Conhecimento. Competências.

1 Referência do texto original: DURU-BELLAT, Marie. Connaissances ou compétences que transmettre?. In: BEDIN, V.; FOURNIER, M. (Org.). Apprendre: Pourquoi? Comment?. Auxerre: Sciences Humaines Éditions, 2014, p. 77-82.

2 Tradução de Fernando Santos; revisão técnica de Vanda Mendes Ribeiro.

3 O resumo foi elaborado pelos editores da Cadernos Cenpec pois não constava no original. 
A questão da transmissão de conhecimento na escola sempre foi objeto de debate. $O$ velho conflito entre os partidários da instrução e os partidários da educação ressurge hoje por meio de críticas virulentas à noção de competência.

Não há nada mais central para a escola do que a tarefa de definir o que se julga bom e necessário de transmitir aos alunos. Os debates em torno daquilo que a escola deve transmitir têm sido marcados, há várias décadas, por uma oposição polêmica: devemos transmitir competências aos alunos - saber extrair uma informação contida em um texto, por exemplo - ou saberes fazer com que aprendam um texto ou um poema de cor? Essa oposição se vincula, sem sombra de dúvida, a diferentes posições ideológicas, mas ela também suscita verdadeiras questões pedagógicas e filosóficas.

\section{A ESCOLA E O MUNDO DO TRABALHO}

O percurso da noção de competência tem início na França no começo dos anos 80, após a escola ter sido abalada por um grande volume de críticas (ROPÉ; TANGUY, 2003). A escola devia aceitar que não possuía mais o monopólio da transmissão de conhecimentos e admitir que os saberes escolares não são nem sagrados nem incontestáveis. Além disso, Pierre Bourdieu e Jean-Claude Passeron marcaram presença nesse movimento (com La Reproduction, publicado em 1970), fazendo com que a crítica à cultura escolar elitista se constitua num elemento obrigatório, sobretudo porque, com a democratização do ensino, a escola secundária passa a não mais receber somente os "herdeiros". Os debates também se situam em um contexto da retomada relativa das relações entre a escola e o mundo do trabalho e de esforços para revalorizar a formação profissional, com o desenvolvimento da formação continuada e da colaboração com os meios empresariais, que trazem para o ambiente escolar questionamentos até então sem sentido: se a alternância pudesse ser "educativa”, o que seria necessário para se inserir na "vida real" $?$

4 De acordo com Teixeira, Bernartt e Trindade (2008), que realizaram levantamento sobre dissertações e teses feitas no Brasil sobre a Pedagogia da Alternância, esta "consiste numa metodologia de organização do ensino escolar que conjuga diferentes experiências formativas distribuídas ao longo de tempos e espaços distintos, tendo como finalidade uma formação profissional.” Duru-Bellat está se referindo a discussões que ocorrem na França em torno da ampliação da formação que conjuga teoria e prática, sendo que as atividades práticas seriam realizadas em empresas ou organizadas de modo a expor os alunos ao mundo do trabalho. Referência: TEIXEIRA, Edival Sebastião; BERNARTT, Maria de Lourdes; TRINDADE, Glademir Alves. Estudos sobre Pedagogia da Alternância 
Tais questionamentos já haviam sido explicitados por pedagogos pro gressistas. Os pedagogos da Nova Escola (Ovide Decroly, Célestin Freinet, John Dewey) preconizavam uma pedagogia ativa que tornasse o aluno autônomo na construção de seus saberes, em outras palavras, muito mais competente do que erudito. A partir dos anos 1970, um grande número de pedagogos passa a dar prioridade às metodologias da aprendizagem ("aprender a aprender") no que tange aos saberes disciplinares, na linha do sociólogo britânico Basil Bernstein. Ele defendia uma pedagogia "visível" que destacasse e explicitasse as aprendizagens, facilitando seu domínio por parte dos alunos mais defasados culturalmente, contrária àquela pedagogia “invisível” opaca e elitista, emblemática das escolas secundárias francesas de então. Pretendia-se com isso substituir a hierarquia dos saberes por uma representação mais horizontal da diversidade de competências, proporcionando, assim, oportunidades a todos.

\section{A CIÊNCIA CONTRA O MERCADO?}

Na França, sob a bandeira de pedagogos como Philippe Meirieu, surgem novos conceitos, como interdisciplinaridade, pedagogia por objetivos ou por contrato, trabalho de grupo, individualização. A prioridade é formar indivíduos autônomos capazes de se virar na vida graças a um leque aberto de savoir-faire e de savoir-être ${ }^{5}$. Ainda que intelectuais como Alain Finkielkraut se enfureçam, em nome da República, contra os pedagogos que atacam os saberes e sacrificam a instrução em nome da educação (FOURNIER, 2007), os documentos oficiais ratificam essa evolução. Na França, o currículo de 1992 consagra a noção de competências exigíveis no fim da formação, fazendo com que esse currículo se torne, assim, um "contrato de ensino", com um aluno que a lei de orientação de 1989 coloca "no centro do sistema".

A noção de competência provocou resistências imediatas. Os professores percebiam claramente que ela veiculava sub-repticiamente uma concepção diferente dos saberes e do papel da escola com a promoção da aprendizagem prática, um paliativo que era avaliado, de certa forma, por sua eficácia, e do qual qualquer aluno independente poderia se beneficiar. Formados no domínio de uma disciplina valorizada em si mesma, tida como a base de sua

no Brasil: revisão de literatura e perspectivas para a pesquisa. Educação e Pesquisa, São Paulo, v. 34, n. 2, Maio/Ago. 2008. [N. do T.].

Savoir-faire é expressão da língua francesa que se reporta a competências adquiridas por meio da experiência e que permitem fazer algo de forma adequada. Savoir-être diz respeito à capacidade de produzir ações e reações adaptadas ao meio. [N. do T.] 
autoridade, os professores não podiam deixar de perceber que isso sinalizava a necessidade de transformação de seu trabalho com os alunos, e contestava a virtude intrinsecamente educativa, democrática e libertadora dos saberes disciplinares, tais como definidos e transmitidos unicamente por eles.

A partir dos anos 2000, a crítica da abordagem por competências assume uma nova aparência: será que ela não consagra a entrada, com força total, do neoliberalismo na escola (LAVAL, 2011; DEL REY, 2010)? Num mundo do trabalho em que as qualificações exigidas são imprevisíveis e variadas, para ser eficaz o trabalhador deve se mobilizar, se mostrar flexível e polivalente. E é justamente para atender a essas necessidades da economia e apoiar o crescimento econômico, árbitro supremo, que a Organização para a Cooperação e Desenvolvimento Econômico (OCDE) se envolveu com as questões de formação, estimulando os Estados a racionalizar seus sistemas educacionais para dotar os jovens de competências das quais eles terão necessidade em sua vida - profissional, em primeiro lugar. Com as pesquisas do Programa Internacional de Avaliação de Alunos (Pisa) lançadas em 2000 sob patrocínio da OCDE, pretende-se avaliar as competências dos alunos de 15 anos em três áreas: compreensão da escrita, matemática e conhecimento científico. Para além dos programas nacionais, o essencial é compreender o que os jovens de 15 anos são capazes de fazer; por exemplo, será que eles são capazes de compreender, utilizar e analisar textos escritos?

Tendo as competências adentrado a escola, instalou-se toda uma maquinaria avaliativa que é um bom motivo para deixar os professores perplexos: como avaliar o nível de domínio de competências fragmentadas e, por vezes, extremamente abstratas como "adaptar sua comunicação em função do contexto"? Aliás, como ter certeza de que as competências que nos esforçamos em avaliar e que seriam a ratificação suprema da eficácia do ensino podem ser transferíveis: o desempenho de um aluno - ele consegue compreender um determinado texto escrito? - garante, para além do exercício realizado com êxito, uma competência geral, quaisquer que sejam os textos e durante toda a vida?

De fato, se despirmos as resistências de seu manto corporativo ou ideológico, a abordagem por competências suscita questões concretas, essenciais para os pedagogos (CRAHAY, 2006). Antes de tudo, a questão da transferência: como fazer para que as aprendizagens realizadas em sala de aula permitam que o aluno aprenda mais tarde, quando tiver necessidade? Mas também, e de maneira mais ampla, como fazer para que esses saberes sejam realmente formadores, isto é, ajudem a criança a se desenvolver e a se inserir na vida? 
São perguntas abrangentes, mas que não podemos escamotear preconizando o retorno ao primado dos saberes: para refletir sobre o que o aluno se torna capaz de realizar graças ao aprendizado, não é possível contrapor saberes e competências. Para conseguir utilizar uma máquina, qualquer que seja ela, não defenderíamos que basta conhecer seu funcionamento no papel (ou ler as instruções), ou, ainda, segundo a abordagem por competências, manipulá-la... O saber desempenha uma função na ação, para desembocar no conhecimento pleno.

\section{UMA DITADURA DO ÚTIL?}

Existe outra questão real relativa ao primado do útil que seria difundido pela abordagem por competências. A retórica do "para que serve isso?" é ainda mais utilizada, uma vez que consideramos, a priori, que os alunos têm pouco interesse pela atividade escolar. Além do mais, o contexto do emprego torna prioritário o caráter "rentável" daquilo que se aprende. Não existe nada de desprezível nisso: ter êxito na vida não se limita a subir na escala social graças aos saberes escolares acumulados; todos precisam encontrar uma possibilidade de emprego no mundo do trabalho tal como ele é. Isso não impede que seja extremamente arriscado delimitar o que é útil hoje com relação às incertezas do amanhã. Além disso, tentar motivar os alunos apelando para o útil os torna utilitaristas e elimina o sentido de todas as aprendizagens cuja utilidade é incerta, sem contar as decepções que a vida lhes reservará com relação a isso.

Nas entrelinhas, existe a questão de saber que educação estaremos defendendo se aceitarmos essa ditadura do útil. A filósofa Martha Nussbaum ${ }^{6}$ denuncia uma educação "voltada para o lucro". Ela defende, ao contrário, uma educação para a democracia, que desenvolva a independência de espírito, a imaginação e a capacidade de empatia, e, para tal, que se baseie nas humanidades e nas artes. Não se trata de defender mais uma disciplina, mas um estado de espírito, convidando os alunos a se colocarem no lugar de um personagem de romance, a analisarem suas emoções diante de uma obra de arte, a se surpreenderem por compreender tão bem os propósitos de um autor - filósofo ou político - que data de muitos séculos... Educar seria também permitir que os alunos sentissem o prazer das descobertas gratuitas, o prazer de superar a dificuldade de um raciocínio, o prazer de compreender, de "reencontrar o sentido dos saberes e da cultura" (GAUCHET, 2011; BLAIS; GAUCHET; OTTAVI, 2014).

\footnotetext{
Para uma introdução a suas teses, ver: «www.laviedesidees.fr/L-utilite-sociale-deshumanites.html>.
} 
Se os debates saberes versus competências são tão intensos é porque eles questionam a natureza, as ambições e as modalidades de uma educação que não se reduz à transmissão de saberes. A noção de competência tem o mérito de explicitar os objetivos visados e, consequentemente, de abrir o debate sobre o que deve ser o projeto educacional de nossa escola: se podemos contestar o caráter democrático das diretivas europeias em matéria de competências a serem transmitidas, será que podemos fazer o mesmo quando se trata do modo como o mundo acadêmico relaciona os saberes disciplinares que devem constar do seu currículo?

Uma verdadeira reflexão sobre a cultura a ser oferecida a todos exige que se deixe para trás a oposição saberes/competências (PERRENOUD, 2006), mas também que nos coloquemos outras questões, talvez (ainda) mais incômodas: a da validade do monopólio da escola e dos especialistas de uma disciplina sobre a educação e a do valor formador de uma educação realizada por meios "puramente intelectuais". 


\section{Knowledge or competencies: what should be transmitted?}

Abstract: Assuming the focus is to define what is considered good and necessary to be transmitted to students, the author reflects on the curricular matter starting from the debate about an old controversy: should we priorize transmission of competencies or transmission of knowledge to students? Author resumes the argument on the notion of competencies and its introduction in school, on the arrival of evaluation systems based on competencies and its operationalizing strategies, on matters that working with the notion at issue here may rise to instructors, and on the existence of what is called a "dictatorship of utility".

Key words: Curriculum. Knowledge. Competencies. 


\section{REFERÊNCIAS}

ROPÉ, F.; TANGUY, L. (Org.). Savoirs et compétences. De l'usage de ces notions dans l'école et l'entreprise. Paris: L'Harmattan, 2003.

GAUCHET, M. Contre l'idéologie de la compétence, l'école doit apprendre à penser, Le Monde, 2 set. 2011.

Blais, M. C.; GAUCHET, M.; OTTAVI, D. Por une philosophie politique de l'éducation, Paris: Bayard, 2002. Transmettre, apprendre. Paris: Stock, 2014.

PERRENOUD, P. Le socle et la statue, Cahiers pédagogiques, n. 439, p. 16-18, 2006.

CRAHAY, M. Dangers, incertitudes et incomplétude de la logique de la connaissance en éducation, Revue française de pédagogie, n. 154, jan./fev. 2006.

FOURNIER, M. École: l'instruction contre l'éducation, Sciences Humaines, n. 178, jan. 2007. 